\title{
Influência do uso e ocupação do solo na disponibilidade hídrica da bacia hidrográfica do Rio Uruçuí-Preto, Piauí
}

\author{
Kaíse Barbosa SOUZA ${ }^{1 *}$, João Batista Lopes SILVA², Rafael Felippe RATKE ${ }^{3}$, \\ Gerson Santos LISBOA ${ }^{4}$, Karla Nayara Santos ALMEIDA ${ }^{3}$
}

\author{
${ }^{1}$ Programa de Pós-Graduação em Ciências Florestais, Universidade Federal do Espírito Santo, Jerônimo Monteiro, ES, Brasil. \\ ${ }^{2}$ Instituto de Humanidades, Artes e Ciências, Universidade Federal do Sul da Bahia, Itabuna, BA, Brasil. \\ ${ }^{3}$ Universidade Federal do Piauí, Bom Jesus, PI, Brasil. \\ ${ }^{4}$ Centro de Formação em Tecno-Ciências e Inovação, Universidade Federal do Sul da Bahia, Itabuna, BA, Brasil. \\ *E-mail: kaisesouza172@yahoo.com.br
}

Recebido em setembro/2018; Aceito em março/2019.

\begin{abstract}
RESUMO: Objetivou-se verificar a influência das mudanças no uso e ocupação do solo na disponibilidade hídrica da bacia hidrográfica do rio Uruçuí-Preto, Piauí, no período de 1984 a 2007. Para a avaliação do uso do solo foram utilizadas imagens do Satélite Landsat 5, sensor TM (Thematic Mapper) e realizou-se a classificação automática supervisionada auxiliada pelo algoritmo de Máxima Verossimilhança. Para a análise do comportamento hidrológico foram utilizados dados da vazão média, máxima e mínima anual; vazão mínima com sete dias de duração anual $\left(\mathrm{Q}_{7}\right)$; e as vazões associadas às permanências de $90 \%\left(\mathrm{Q}_{90}\right)$ e $95 \%\left(\mathrm{Q}_{95}\right)$. Para a associação entre as vazões e o uso do solo, fez-se a correlação simples entre as variáveis, testando seu nível de significância a 5\% $(\mathrm{p}<0,05)$ de probabilidade. Os resultados demonstraram que ao comparar os anos de 1984 e 2007, as classes Cerrado e Mata Ciliar reduziram 20,9\% e 2,4\% respectivamente, a classe Solo Exposto/Talhão Agrícola aumentou 13,48\% e a classe Queimada aumentou 9,83\%. Não ocorreram correlações significativas entre as variáveis classes de mudanças no uso e ocupação do solo e as vazões, devido a extensa área da bacia que amenizou consequentemente os efeitos hidrológicos.
\end{abstract}

Palavras-chave: desmatamento; sensoriamento remoto; vazões.

\section{Influence of the land use and occupation in hidrologic availability of river basin Uruçuí-Preto, Piauí}

\begin{abstract}
The aim's was to verify the influence of changes in land use and occupation in water availability in the river basin Uruçuí-Preto, Brazil, in the period 1984 to 2007. For the assessment of land use were used images from satellite Landsat 5 TM sensor (Thematic Mapper) and the classification of imagens was made by automatic supervised classification with the maximum likelihood algorithm. For the analysis of the hydrological behavior were used average flow data, maximum and minimum annual, minimum flow with seven days of annual duration (Q7) and flow rates associated with stays of 90\% (Q90) and 95\% (Q95) of the year. For the association between flow and land use was made the simple correlation between the variables, testing its $5 \%$ significance (p $<0.05)$. The results showed that when comparing the years 1984 and 2007, the Cerrado and Mata Riparian classes decreased 20.9\% and 2.4\% respectively, Solo Exposed / Crop Field class increased 13.48\% and Burned Areas class increased by $9.83 \%$. There were no significant correlations between changes of class variables in the use and occupation of land and the flows, due to the large area of the basin that has consequently reduced the hydrological effects.
\end{abstract}

Keywords: deforestation; remote sensing; flow.

\section{INTRODUÇÃO}

A manutenção em padrões de quantidade e qualidade da água representa um desafio para a sociedade (BRASIL, 2006), que têm como objetivo o atendimento aos seus múltiplos usos. Assim, discutir e propor soluções para os problemas relativos às bacias hidrográficas, visando a sustentabilidade do uso da água, são objetivos que o planejamento e a gestão dos recursos hídricos devem assegurar às futuras gerações.

A disponibilidade hídrica de uma bacia pode ser compreendida pela análise da variabilidade das precipitações e das vazões mínimas, médias, máximas conforme descrito por Araújo; Rocha (2010). As vazões mínimas são definidas por meio de valores numéricos que representam a quantidade de água que permanece no leito do rio em épocas de estiagem, ou a água que permaneceu no corpo hídrico após retiradas para diversos fins externos (ALMEIDA et al., 2014).

A vazão média expressa a máxima disponibilidade hídrica de uma bacia, pois esta é a maior vazão que pode ser regularizada em um curso de água (MOREIRA et al., 2014). As vazões máximas são de extrema importância para a estimativa de cheias e para o dimensionamento de obras hidráulicas (TUCCI, 2009). Por sua vez, as vazões de referência são índices de vazão que são adotados para fins de outorga pelos órgãos gestores de recursos hídricos influenciando diretamente no total disponível para outorga (SILVA et al., 2015b). 
O regime hídrico ou as vazões de um rio podem ser afetadas por diversos fatores, tais como: o uso do solo, variabilidade climática, captações de água, barragens, mudanças climáticas, entre outros (SANTOS et al., 2010). Dessa forma, modificações no uso e ocupação do solo praticadas em uma bacia hidrográfica tendem a promover mudanças quantitativas e qualitativas sobre os processos hidrológicos (BUTT et al., 2015). As ações antrópicas, como por exemplo, o aumento da produção de bens agrícolas, têm gerado grandes impactos nas paisagens, como perda da biodiversidade e deterioração da qualidade e quantidade dos recursos hídricos (DELLAMATRICE; MONTEIRO, 2014; PULLANIKKATIL et al., 2016).

Assim, a análise do comportamento hidrológico resultante de alterações no uso e ocupação dos solos é de grande importância para o gerenciamento adequado dos recursos hídricos, possibilitando inferir sobre a disponibilidade hídrica e tornando-se ferramenta essencial no estabelecimento de medidas visando o desenvolvimento sustentável. O monitoramento das mudanças ocorridas sobre a superfície terrestre por meio do sensoriamento remoto vem sendo bastante utilizado em virtude do baixo custo e rapidez na obtenção dos resultados (NERY et al., 2014, ZHU; LIU, 2015), onde o uso desta ferramenta geotecnológica, concomitante aos Sistemas de Informações Geográficas, possibilita fornecer informações sobre os riscos de degradação ambiental (AQUINO et al., 2016), auxiliando assim na tomada de decisões.

Nesse contexto de alteração do uso e ocupação do solo, destaca-se a bacia do rio Uruçuí-Preto, que entre 1984 e 2010 sofreu grandes alterações em sua cobertura vegetal nativa, devido a implantação de culturas agrícolas, tendo algumas sub-bacias perdido entre 30 a $45 \%$ da vegetação nativa (SILVA et al., 2014; SILVA et al., 2015a).

A bacia do rio Uruçuí-Preto é uma região que se destaca pela expansão agrícola e devido a sua importância econômica para o Estado do Piauí evidencia-se a necessidade de se conhecer as alterações no uso do solo e sua influência no comportamento hidrológico. Assim, objetivou-se verificar a influência das mudanças no uso e ocupação do solo na disponibilidade hídrica da bacia hidrográfica do rio UruçuíPreto, Piauí, no período de 1984 a 2007.

\section{MATERIAL E MÉTODOS}

\subsection{Caracterização da área de estudo}

A bacia hidrográfica do rio Uruçuí-Preto está localizada no Oeste do Estado do Piauí, com área total de $15.777 \mathrm{~km}^{2}$, representando $6,3 \%$ do território piauiense. Está entre as latitudes Sul de $07^{\circ} 18^{\prime} 16^{\prime \prime}$ a 09 33'06' e longitudes Oeste de 4415'30' a 45³1'11'" (MEDEIROS et al., 2013). A bacia é drenada pelo rio Uruçuí-Preto e encontra-se na bacia sedimentar do rio Parnaíba, constituindo-se como um dos principais tributários pela margem direita (Figura 1).

A temperatura média anual na bacia hidrográfica é de $26,1^{\circ}$ C, e segundo a classificação climática de Köppen, existem dois tipos climáticos: o Aw, tropical quente e úmido, com chuvas no verão e seca no inverno; e o BSh, semiárido quente, com chuvas de verão e inverno seco. Entre os meses de novembro a março os volumes pluviométricos são elevados e nos meses de abril a outubro a bacia hidrográfica do rio Uruçuí-Preto sofre com a escassez de água, sendo que estas características climáticas causam uma alta variabilidade na vazão dos mananciais (MEDEIROS et al., 2013).
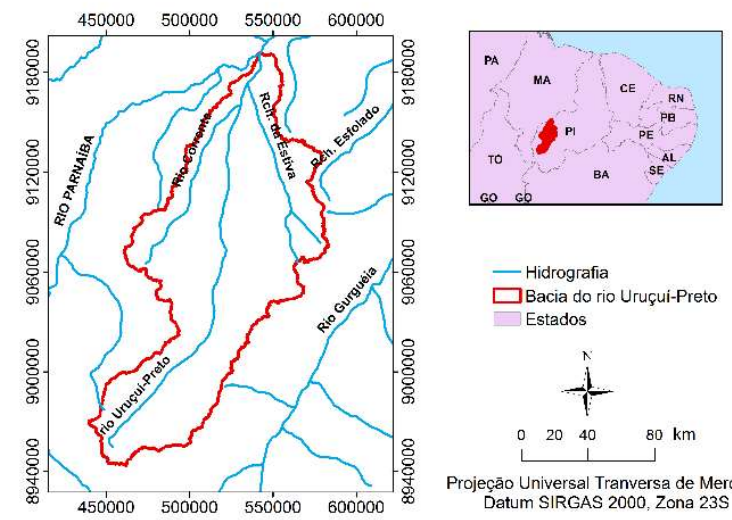

Figura 1. Localização da bacia hidrográfica do rio Uruçuí-Preto. Figure 1. Geographic location of the basin of Uruçuí-Preto River.

2.2. Análise do comportamento hidrológico da bacia do rio Uruçuí-Preto

A série de dados de vazões diárias entre 1984 a 2007 foi proveniente da estação fluviométrica Fazenda Bandeira (código 34090000), sendo obtida no Sistema de Informações Hidrológicas (Hidroweb), da Agência Nacional de Águas (ANA). A partir da série histórica obteve-se a vazão média anual $\left(Q_{\text {med }}\right)$, a vazão máxima anual $\left(Q_{\max }\right)$, a vazão mínima anual $\left(\mathrm{Q}_{\text {min }}\right)$, a vazão mínima com sete dias de duração anual $\left(\mathrm{Q}_{7}\right)$, e as vazões associadas às permanências de $90 \%\left(\mathrm{Q}_{90}\right)$ e $95 \%\left(Q_{95}\right)$ de cada ano. As vazões associadas à permanência de $90 \%$ e $95 \%$ anuais foram obtidas pelas curvas de permanência da estação fluviométrica com base em dados diários de cada ano. Todos estes dados foram processados utilizando-se o software SisCAH 1.0.

\subsection{Processamento digital das imagens}

Para identificação do uso e ocupação do solo foram utilizadas imagens, disponibilizadas pelo Instituto Nacional de Pesquisas Espaciais (INPE), do Satélite Landsat 5, sensor TM (Thematic Mapper) entre o período de 1984 a 2007, devido ao início da operação do Landsat 5 ser o ano de 1984 e o final dos dados consistidos de vazão utilizados neste estudo serem 2007. Foram utilizadas as imagens da órbita 220 , em três pontos (065, 066 e 067), sendo o período analisado anualmente, sempre com imagens entre os meses de maio a agosto, tendo em vista ser o final da colheita agrícola na região.

No pré-processamento das imagens realizou-se a composição colorida RGB 342, o qual realça a vegetação em relação às demais classes e foram aplicados a correção geométrica nas mesmas. Para o ano de 1984, o georreferenciamento da imagem foi realizado com base na hidrografia da bacia gerada pelo Modelo Digital de Elevação Hidrologicamente Consistente (MDEHC) da base Shuttle Radar Topography Mission (SRTM). Após o georreferenciamento da imagem de 1984, esta foi utilizada para o georreferenciamento das imagens dos demais anos e em seguida fez-se a extração da área de interesse, no caso a bacia hidrográfica do rio Uruçuí-Preto. 
Após o pré-processamento das imagens, fez-se a análise e classificação das imagens por classificação automática supervisionada auxiliada pelo algoritmo de Máxima Verossimilhança. A rotulação dos pixels foi composta por quatro classes que levou em consideração o impacto ambiental, o avanço da agricultura e a semelhança de resposta espectral entre as diferentes superfícies conforme Silva et al. (2015a) (Tabela 1). Após a classificação das imagens foi realizado o cálculo de área para cada classe para cada ano analisado.

Todas as etapas do processamento digital das imagens foram realizadas no software de Sistemas de Informações Geográficas ESRI ArcGIS 10, com o auxílio da extensão Spatial Analyst.

Tabela 1. Classes utilizadas na classificação das imagens.

Table 1. Land uses classes in images of classification.

\begin{tabular}{|c|c|}
\hline Classes & Descrição \\
\hline Cerrado & etação nc \\
\hline Mata ciliar & $\begin{array}{l}\text { com vegetação nativa adjacente aos cursos } \\
\text { a }\end{array}$ \\
\hline Queimada & $\begin{array}{l}\text { Áreas sem vegetação, que foram destruídas pelo } \\
\text { fogo }\end{array}$ \\
\hline $\begin{array}{l}\text { Solo exposto/ } \\
\text { Talhão agrícola }\end{array}$ & $\begin{array}{l}\text { Áreas com solo exposto e/ou com cultivo } \\
\text { agrícola }\end{array}$ \\
\hline
\end{tabular}

\subsection{Associação entre vazões e uso e ocupação do solo}

A fim de se analisar a relação entre as vazões e as classes de uso do solo, realizou-se inicialmente a análise exploratória dos dados constituídos de valores mínimos e máximos seguidos da média, desvio padrão, coeficiente de variação e erro padrão da média.

Logo após realizou-se a correlação simples (r) entre as variáveis testando seu nível de significância a 5\% $(\mathrm{p}<0,05)$ de probabilidade, tendo este procedimento sido realizado no software SAS 9.0, utilizando-se a ferramenta PROC CORR.

\section{RESULTADOS}

3.1. Comportamento das classes de uso e ocupação do solo e das variáveis hidrológicas

Pela análise exploratória dos dados, observou-se que a variável queimada apresentou o maior coeficiente de variação
(CV), (Tabela 2) e que de modo geral, as classes de uso e ocupação do solo apresentaram os maiores coeficientes de variação do que as vazões analisadas.

Em relação as vazões, as vazões máximas apresentaram a maior variação no decorrer do período analisado, apresentando valores extremos, sendo os maiores valores para os anos de $1985,1990,1992$ e 2004, variando entre 100,51 a $116,81 \mathrm{~m}^{3} \mathrm{~s}$ ${ }^{1}$ e os menores valores ocorreram nos períodos de 1987, 1993, 1996, 1998 e 2001, variando entre 53,66 a 58,77 $\mathrm{m}^{3} \mathrm{~s}^{-1}$ (Tabela 3). Em relação as vazões mínimas anuais, estas sofreram pequenas variações onde o maior valor registrado foi em 1989 representando $27,01 \mathrm{~m}^{3} \mathrm{~s}^{-1}$ e o menor valor foi registrado no ano de 2007, 19,19 $\mathrm{m}^{3} \mathrm{~s}^{-1}$. Já as vazões médias também apresentaram variações, onde o ano de 2007 apresentou o menor valor registrado, $28,81 \mathrm{~m}^{3} \mathrm{~s}^{-1}$ e o maior valor foi no ano de $1985,42,17 \mathrm{~m}^{3} \mathrm{~s}^{-1}$. Quanto às vazões mínimas de referência, na $\mathrm{Q}_{95}$ anual houve variações onde o ano de 1984 apresentou menor valor correspondente a $22,06 \mathrm{~m}^{3} \mathrm{~s}^{-1}$ e o ano de 1989 apresentou maior valor, 28,23 $\mathrm{m}^{3} \mathrm{~s}^{-1}$. Para a vazão mínima $\mathrm{Q}_{90}$ anual o maior valor ocorreu em 1989, 29,23 $\mathrm{m}^{3} \mathrm{~s}^{-1}$ e o menor valor em $1984 \mathrm{com} 22,45 \mathrm{~m}^{3} \mathrm{~s}^{-1}$. Em relação a vazão mínima $\mathrm{Q}_{7}$ anual o ano de 1989 também apresentou o maior valor, $27,77 \mathrm{~m}^{3} \mathrm{~s}^{-1}$, mas o menor valor foi referente ao ano de 2005 , $21,70 \mathrm{~m}^{3} \mathrm{~s}^{-1}$.

3.2. Classificação e variabilidade das classes de uso e ocupação do solo

A classe Cerrado sofreu redução das áreas no período analisado, pois entre os anos 1984 e 2007 houve uma redução relevante de $3.332,96 \mathrm{~km}^{2}$ de área de vegetação, ou seja, $20,90 \%$, com exceção para os anos de 1987, 1989, 1991 e 1995, quando houve aumento das áreas de Cerrado (Tabela 4). A redução mais crítica para esta classe ocorreu entre os anos de 1992 e 1993, transitando de $10.175,59 \mathrm{~km}^{2}$ para $6.677,78 \mathrm{~km}$ (redução de 21,94\%).

As áreas de solo exposto/talhão agrícola aumentaram ao se comparar os anos de 1984 e 2007, ocorrendo um aumento estimado em $2.149,17 \mathrm{~km}^{2}, 13,48 \%$ da área total da bacia (Tabela 4). O maior acréscimo ocorreu entre os anos 1992 e 1993, transitando de $4.798,01 \mathrm{~km}^{2}$ para $8.062,81 \mathrm{~km}^{2}$, correspondente a um aumento de $20,47 \%$.

Tabela 2. Estatísticas descritivas de todas as classes de uso e ocupação do solo e vazões.

Table 2. Descriptive statistics of all classes of land use and occupation and flows.

\begin{tabular}{|c|c|c|c|c|c|c|c|}
\hline Variáveis & $\mathrm{N}$ & Mínimo & Máximo & Média & $\mathrm{S}$ & $\mathrm{CV}(\%)$ & EPM \\
\hline Solo Exposto/Talhão Agrícola & 23 & $4.362,00$ & $9.025,00$ & $6.451,00$ & $1.292,00$ & 20,03 & 269,35 \\
\hline Queimada & 23 & 0,00 & $2.280,00$ & 280,97 & 554,10 & 197,21 & 115,54 \\
\hline Mata Ciliar & 23 & 376,43 & $2.949,00$ & $1.341,00$ & 488,95 & 36,46 & 101,95 \\
\hline Cerrado & 23 & $5.529,00$ & $10.239,00$ & $7.875,00$ & $1.493,00$ & 18,96 & 311,36 \\
\hline $\mathrm{Q}_{\max }$ & 23 & 53,66 & 116,81 & 76,32 & 18,38 & 24,08 & 3,83 \\
\hline$Q_{\min }$ & 23 & 19,19 & 27,01 & 23,39 & 1,83 & 7,82 & 0,38 \\
\hline $\mathrm{Q}_{\text {med }}$ & 23 & 28,81 & 42,17 & 35,64 & 3,45 & 9,69 & 0,72 \\
\hline $\mathrm{Q}_{95}$ & 23 & 22,06 & 28,23 & 24,26 & 1,72 & 7,07 & 0,36 \\
\hline $\mathrm{Q}_{90}$ & 23 & 22,45 & 29,23 & 24,89 & 1,78 & 7,16 & 0,37 \\
\hline $\mathrm{Q}_{7}$ & 23 & 19,23 & 27,77 & 23,62 & 1,90 & 8,06 & 0,40 \\
\hline
\end{tabular}

em que: $\mathrm{N}$ = número de observações, anos; $\mathrm{CV}=$ coeficiente de variação; $\mathrm{S}=$ desvio padrão; e EPM = erro padrão da média.

A classe Mata Ciliar apresentou intensa variação no decorrer dos anos, onde ocorreu alternância entre aumento e redução em praticamente todos os anos, fato que pode ser observado pelo alto coeficiente de variação (36,46\%) (Tabela 2). Comparando o ano de 1984 e 2007, houve uma diminuição de $383,46 \mathrm{~km}^{2}$, ou seja, 2,4\% (Tabela 4). A maior redução ocorreu entre os anos 2003 e 2004, transitando de $1.753,9 \mathrm{~km}^{2}$ para 1.017,51 km², ou seja, uma redução de 4,62\%.

Em relação à classe Queimadas, no decorrer dos anos houve variação das áreas como pode ser observado pelo alto 
coeficiente de variação (Tabela 2), com exceção para os anos 1984, 1989, 1993, 1995, 2004, 2005 e 2006 em que não se apresentou vestígios de incêndios. $\mathrm{O}$ maior foco de queimadas ocorreu em 1990, estimado em 2.280,47 km² (14,30\%), sendo este também o maior acréscimo e o segundo maior foco ocorreu em 2007, estimado em 1.567,24 km² (Tabela 4).

Tabela 3. Quantificação das vazões $\left(\mathrm{m}^{3} \mathrm{~s}^{-1}\right)$ no período de 1984 a 2007.

Table 3. Quantification of flows $\left(\mathrm{m}^{3} \mathrm{~s}^{-1}\right)$ for the period 1984-2007.

\begin{tabular}{ccccccc}
\hline Ano & Máxima $\left(\mathrm{Q}_{\max }\right)$ & Mínima $\left(\mathrm{Q}_{\min }\right)$ & Média $\left(\mathrm{Q}_{\operatorname{med}}\right)$ & $\mathrm{Q}_{95}$ & $\mathrm{Q}_{90}$ & $\mathrm{Q}_{7}$ \\
\hline 1984 & 66,04 & 21,70 & 31,07 & 22,06 & 22,45 & 22,03 \\
1985 & 101,67 & 24,07 & 42,17 & 25,39 & 26,34 & 24,38 \\
1986 & 72,89 & 24,79 & 37,08 & 25,79 & 26,46 & 25,18 \\
1987 & 58,44 & 22,40 & 32,63 & 23,47 & 24,13 & 22,70 \\
1988 & 68,75 & 24,79 & 36,88 & 25,52 & 26,26 & 25,04 \\
1989 & 97,04 & 27,01 & 41,79 & 28,23 & 29,23 & 27,77 \\
1990 & 100,51 & 26,76 & 37,74 & 27,31 & 27,85 & 26,76 \\
1991 & 65,03 & 24,31 & 36,81 & 25,25 & 26,10 & 24,51 \\
1992 & 116,81 & 23,83 & 36,88 & 24,53 & 25,08 & 24,07 \\
1993 & 56,19 & 23,11 & 31,84 & 23,87 & 24,34 & 23,18 \\
1994 & 64,03 & 22,40 & 33,55 & 23,30 & 23,70 & 22,64 \\
1995 & 63,69 & 23,35 & 36,74 & 23,76 & 24,53 & 23,42 \\
1996 & 58,77 & 21,70 & 35,85 & 23,56 & 24,58 & 22,23 \\
1997 & 87,25 & 25,52 & 38,90 & 26,29 & 26,59 & 25,88 \\
1998 & 53,66 & 22,40 & 32,29 & 23,05 & 23,35 & 22,74 \\
1999 & 81,40 & 23,11 & 36,90 & 23,84 & 24,41 & 23,28 \\
2000 & 86,15 & 25,28 & 40,88 & 25,92 & 26,78 & 25,59 \\
2001 & 54,29 & 24,31 & 33,95 & 24,72 & 25,03 & 24,34 \\
2003 & 70,12 & 21,70 & 32,85 & 22,47 & 23,22 & 21,73 \\
2004 & 107,17 & 22,64 & 36,82 & 23,10 & 23,54 & 22,84 \\
2005 & 79,60 & 21,70 & 34,92 & 22,17 & 22,87 & 21,70 \\
2006 & 83,58 & 21,93 & 22,36 & 22,20 & 22,87 & 22,03 \\
2007 & 62,37 & 19,19 & & 22,20 & 22,87 & 22,87 \\
\hline
\end{tabular}

Tabela 4. Quantificação nas classes de uso e ocupação do solo $\left(\mathrm{km}^{2}\right.$ e porcentagem) da bacia hidrográfica do rio Uruçuí-Preto, durante o período de 1984 a 2007.

Table 4. Quantification in the land use and occupation classes ( $\mathrm{km}^{2}$ and percentage) of the Uruçuí-Preto river basin, during the period 19842007.

\begin{tabular}{|c|c|c|c|c|c|c|c|c|}
\hline \multirow{2}{*}{ Ano } & \multicolumn{2}{|c|}{ Cerrado } & \multicolumn{2}{|c|}{ Solo exposto/Talhão Agrícola } & \multicolumn{2}{|c|}{ Mata ciliar } & \multicolumn{2}{|c|}{ Queimadas } \\
\hline & $\mathrm{km}^{2}$ & $\%$ & $\mathrm{~km}^{2}$ & $\%$ & $\mathrm{~km}^{2}$ & $\%$ & $\mathrm{~km}^{2}$ & $\%$ \\
\hline 1984 & $9.719,74$ & 60,95 & $5.468,29$ & 34,29 & 759,89 & 4,76 & 0,00 & 0,00 \\
\hline 1985 & $8.697,64$ & 54,54 & $5.614,94$ & 35,21 & $1.556,80$ & 9,76 & 78,54 & 0,49 \\
\hline 1986 & $8.131,37$ & 50,99 & $6.656,26$ & 41,74 & $1.077,51$ & 6,76 & 82,78 & 0,52 \\
\hline 1987 & $9.855,02$ & 61,80 & $4.362,19$ & 27,35 & $1.548,03$ & 9,71 & 182,67 & 1,15 \\
\hline 1988 & $8.217,86$ & 51,53 & $6.104,79$ & 38,28 & $1.512,37$ & 9,48 & 112,91 & 0,71 \\
\hline 1989 & $8.578,25$ & 53,79 & $6.478,87$ & 40,63 & 890,80 & 5,59 & 0,00 & 0,00 \\
\hline 1990 & $6.151,58$ & 38,57 & $6.285,10$ & 39,41 & $1.230,76$ & 7,72 & $2.280,47$ & 14,30 \\
\hline 1991 & $10.239,04$ & 64,20 & $4.376,13$ & 27,44 & $1.251,50$ & 7,85 & 81,25 & 0,51 \\
\hline 1992 & $10.175,59$ & 63,81 & $4.798,01$ & 30,09 & 914,58 & 5,73 & 59,73 & 0,37 \\
\hline 1993 & $6.677,78$ & 41,87 & $8.062,81$ & 50,56 & $1.207,33$ & 7,57 & 0,00 & 0,00 \\
\hline 1994 & $5.528,97$ & 34,67 & $9.025,12$ & 56,59 & $1.246,59$ & 7,82 & 147,23 & 0,92 \\
\hline 1995 & $10.047,03$ & 63,00 & $4.660,43$ & 29,22 & $1.240,46$ & 7,78 & 0,00 & 0,00 \\
\hline 1996 & $8.977,67$ & 56,29 & $5.566,72$ & 34,91 & $1.374,74$ & 8,62 & 28,80 & 0,18 \\
\hline 1997 & $8.701,45$ & 54,56 & $5.348,09$ & 33,53 & $1.493,06$ & 9,36 & 405,32 & 2,54 \\
\hline 1998 & $7.835,11$ & 49,13 & $6.280,39$ & 39,38 & $1.630,18$ & 10,22 & 202,25 & 1,27 \\
\hline 1999 & $6.750,47$ & 42,33 & $7.661,64$ & 48,04 & $1.282,87$ & 8,04 & 252,94 & 1,59 \\
\hline 2000 & $7.031,60$ & 44,09 & $6.935,80$ & 43,49 & $1.264,53$ & 7,93 & 715,99 & 4,49 \\
\hline 2001 & $7.453,84$ & 46,74 & $7.008,06$ & 43,94 & $1.304,51$ & 8,18 & 181,51 & 1,14 \\
\hline 2003 & $7.117,52$ & 44,63 & $6.993,91$ & 43,85 & $1.753,90$ & 11,00 & 82,59 & 0,52 \\
\hline 2004 & $6.800,88$ & 42,64 & $8.129,53$ & 50,98 & $1.017,51$ & 6,38 & 0,00 & 0,00 \\
\hline 2005 & $6.055,60$ & 37,97 & $7.933,53$ & 49,75 & $1.958,80$ & 12,28 & 0,00 & 0,00 \\
\hline 2006 & $5.987,35$ & 37,54 & $7.011,32$ & 43,96 & $2.949,25$ & 18,49 & 0,00 & 0,00 \\
\hline 2007 & $6.386,78$ & 40,05 & $7.617,46$ & 47,76 & 376,43 & 2,36 & $1.567,24$ & 9,83 \\
\hline
\end{tabular}

3.3. Associação entre as classes de uso e ocupação do solo e variáveis hidrológicas

Pelas correlações simples (r) calculadas entre todas as variáveis analisadas, ocorreu correlação negativa e significativa entre as classes de uso e ocupação do solo: Solo Exposto/Talhão Agrícola e Cerrado, reforçando os dados apresentados anteriormente na Tabela 4. As vazões somente apresentaram correlações positivas e significativas com outras vazões estudas (Tabela 5). Não ocorreram correlações significativas entre as variáveis de classes de mudanças no uso e ocupação dos solos e as vazões (Tabela 5), porém não se pode afirmar que a mudança no uso e ocupação do solo não afeta a disponibilidade hídrica da bacia do rio Uruçuí-Preto.

As vazões máximas não apresentaram correlação significativa com as áreas de Cerrado, pois as vazões máximas variaram bastante, mas não aumentaram com a redução da vegetação nativa. Em relação a classe solo exposto esta também não apresentou correlação visto que as vazões 
máximas deveriam aumentar concomitante ao aumento das áreas de solo exposto.

A classe Mata Ciliar no ano de 1992 apresentou considerável redução, enquanto a vazão máxima apresentou o maior valor, $116,81 \mathrm{~m}^{3} \mathrm{~s}^{-1}$. Já no ano de 1998 a vazão máxima apresentou o menor valor, $53,66 \mathrm{~m}^{3} \mathrm{~s}^{-1}$, enquanto que no mesmo ano ocorreu um aumento da classe Mata Ciliar.
Entre a classe Cerrado e vazão média, deveria ocorrer uma correlação negativa, onde com o aumento das áreas de Cerrado espera-se uma redução nos valores da vazão média, conforme Collischonn et al. (2001).

De forma geral as classes de uso e ocupação do solo não apresentaram correlação com as vazões e consequentemente com a inercia hídrica da bacia.

Tabela 5. Correlação simples (r) entre as variáveis analisadas.

Table 5. Simple correlation (r) between the variables.

\begin{tabular}{lllllllllll} 
& SoloExp & Queim & Mata & Cerrado & Qmax & Qmin & Qmed & Q95 & Q90 & Q7 \\
\hline SoloExp & 1.0000 & 0.0878 & 0.0332 & $-0.9085^{* * *}$ & -0.0252 & -0.2510 & -0.2389 & -0.2624 & -0.2853 & -0.2691 \\
Queim & & 1.0000 & -0.2816 & -0.3548 & 0.1505 & 0.1399 & -0.0391 & 0.2614 & 0.2409 & 0.1039 \\
Mata & & & 1.0000 & -0.2517 & -0.0348 & -0.0670 & -0.0352 & -0.2237 & -0.2071 & -0.0848 \\
Cerrado & & & & 1.0000 & -0.0226 & 0.1872 & 0.2327 & 0.2032 & 0.2253 & 0.2220 \\
Qmax & & & & & 1.0000 & $0.4341^{*}$ & $0.6313^{* *}$ & 0.4045 & 0.4065 & $0.4307^{*}$ \\
Qmin & & & & & & 1.0000 & $0.7867^{* * *}$ & $0.9469^{* * *}$ & $0.9247^{* * *}$ & $0.9959^{* * *}$ \\
Qmed & & & & & & & 1.0000 & $0.7882^{* * *}$ & $0.8140^{* * *}$ & $0.8015^{* * *}$ \\
Q95 & & & & & & & & 1.0000 & $0.9929^{* * *}$ & $0.9541^{* * *}$ \\
Q90 & & & & & & & & & 1.0000 & $0.9351^{* * *}$ \\
Q7 & & & & & & & & 1.0000 \\
\hline
\end{tabular}

em que: SoloExp = classe Solo Exposto/Talhão Agrícola; Queim = classe Queimadas; Mata = classe Mata Ciliar; Cerrado= classe Cerrado; Qmax = vazão máxima; Qmin= vazão mínima; Qmed= vazão média; Q95= vazão associada a 95\% do tempo de ocorrência; Q90 = vazão associada a 90\% do tempo de ocorrência; Q7 = vazão mínima média observada em sete dias consecutivos; * = significativo a $5 \%$ de probabilidade; ** = significativo a $1 \%$ de probabilidade; $* * *$ = significativo a $0,1 \%$ de probabilidade.

\section{DISCUSSÃO}

Ao avaliar comportamento das as classes de uso e ocupação do solo e das variáveis hidrológicas, com base na análise exploratória dos dados, observou-se que a variável Queimada apresentou o maior coeficiente de variação, devido ao comportamento da variável que somente em alguns anos apresentou áreas queimadas (Tabela 2). De modo geral, as variáveis de uso e ocupação do solo apresentaram os maiores coeficientes de variação, ocasionado principalmente em função da dinâmica que a vegetação da região possui em razão do regime de precipitação, com exceção da vazão máxima (Qmax) que apresenta natureza de valores discrepantes. Devido ao regime de chuvas que ocorre entre outubro a maio, sendo que os meses de junho a setembro o volume precipitado é mínimo, a vegetação, um ecótono entre caatinga e cerrado, perde todas as suas folhas durante este período de seca, voltando a emitir folhas no período chuvoso.

Quanto a classificação e variabilidade das classes de uso e ocupação do solo, a redução das áreas de Cerrado ocorreu devido ao desmatamento para fins agrícolas na região, ocorrendo uma inversão entre 1984 e 2007 com as áreas de Solo Exposto/Talhão Agrícola (Tabela 4). Este desmatamento acentuado na região ocorreu devido a expansão da atividade agrícola que iniciou em meados da década de 1970 e foi intensificada na década de 90, com a produção de grãos, principalmente soja, o que impulsionou a agricultura no Estado (SANTOS, 2015). Exemplo disto, o Piauí é o $3^{\circ}$ Estado nordestino na produção de soja, o $2^{\circ}$ Estado nordestino na produção de arroz, o $3^{\circ}$ maior produtor regional de milho e o $4^{\circ}$ maior produtor regional de feijão (PIAUÍ, 2016).

Em relação ao aumento das áreas de solo exposto/talhão agrícola (Tabela 4), é importante salientar que muitas áreas de solo exposto são áreas agrícolas, logo este aumento pode ser atribuído ao aumento das áreas agrícolas e redução da vegetação natural. O que corrobora com França et al. (2017) que verificou a supressão da vegetação nativa da região ocasionada principalmente pela crescente expansão agrícola no município de Uruçuí.

A intensa variação no decorrer dos anos para a classe Mata Ciliar, justifica-se pelo fato que em alguns anos o aumento destas áreas ocorreu devido a dinâmica da vegetação e, também a áreas Cerrado com alta densidade arbórea terem sido classificadas como Mata Ciliar, aumentando assim os valores das áreas enquanto que a redução está associada ao aumento áreas de solo exposto da região.

Para a classe Queimadas, cujo comportamento apresentou variações em áreas e os maiores focos ocorreram em 1990 e 2007 (Tabela 4), Silva et al. (2015a) também constataram resultados semelhantes a este trabalho, ao analisar a evolução temporal do desmatamento na bacia do riacho da Estiva, afluente do rio Uruçuí-Preto. Os resultados comprovam também que em 1984 não há indícios de queimadas e que 1990 apresentou o maior foco de queimadas. Silva et al. (2014) ao analisar a evolução temporal do desmatamento e expansão agrícola entre 1984 a 2010 na sub-bacia do rio Uruçuí-Preto, Piauí, também constataram que entre os anos de 1984 e 1990 houve aumento das áreas afetadas por queimadas.

Ao analisar a associação entre as classes de uso e ocupação do solo e variáveis hidrológicas, pelas correlações simples (r) calculadas entre todas as variáveis avaliadas, a correlação negativa e significativa entre as classes Solo Exposto/Talhão Agrícola e Cerrado (Tabela 5), reforça os dados apresentados anteriormente, onde as áreas de Cerrado foram substituídas por áreas agrícolas, Solo Exposto/Talhão agrícola (Tabela 4). As correlações positivas e significativas entre as vazões eram previstas, pois quando o volume precipitado aumenta todas as vazões aumentam também, incluindo as vazões mínimas, o mesmo ocorre quando o volume precipitado diminui, reduzindo todas as vazões (Tabela 5).

A falta de correlações significativas entre as variáveis de classes de mudanças no uso e ocupação dos solos e as vazões (Tabela 5) não permite afirmar que a mudança no uso e 
ocupação do solo não afeta a disponibilidade hídrica da bacia do rio Uruçuí-Preto. A falta de correlação significativa, ou a baixa correlação, também foi observada por Vanzela et al. (2010), no qual ocorreu correlação baixa, porém significativa, somente com algumas classes de uso e ocupação do solo, diferentes das classes deste trabalho.

Almeida (2007) também não associou o aumento do desflorestamento a aumentos nos valores de vazão ao analisar a influência do desmatamento na disponibilidade hídrica da bacia hidrográfica do Córrego do Galo, Domingos Martins, Espírito Santo. O mesmo autor afirma que com relação a vazão, a não correlação com o desmatamento pode ser explicada por vários fatores, como o tamanho da bacia.

Bosch \& Hewlett (1982) afirmam que os trabalhos que associam o aumento do desflorestamento a aumentos nos valores de vazão são resultantes de trabalhos realizados em bacias menores que $1 \mathrm{~km}^{2}$ e Costa et al. (2003) também afirmam que nestes trabalhos havia controle das condições que exercem influência no processo, o que não ocorre na realidade. Hewlett (1982) afirma que em relação a não correlação da resposta hidrológica com o desmatamento também ocorre pelo fato de que a mesma é em geral controlada principalmente pela geologia e menos pelo uso da terra, em especial em bacias grandes.

Em relação as vazões máximas, esperava-se correlação significativa com as áreas de Cerrado e Solo exposto, porém isto não foi observado. Tucci (2002) afirma que experimentos que obtiveram aumento ou diminuição das vazões mínimas após o desmatamento da bacia hidrográfica, estão relacionados com as alterações na superfície do solo após o desmatamento. Quando as condições de infiltração após o desmatamento são mantidas e, por consequência, a taxa de infiltração, ocorre aumento da recarga em detrimento da redução da evapotranspiração, aumentando as vazões mínimas; por outro lado, se as condições de infiltração são prejudicadas, o escoamento superficial aumenta, reduzindo a recarga do aquífero e, por consequência, ocorre o aumento das vazões máximas. Mas, estas afirmativas não foram observadas neste trabalho, possivelmente em razão do tamanho da bacia hidrográfica do rio Uruçuí-Preto.

Para a classe Mata Ciliar e embora esta não ter apresentado correlação, a mata ciliar representa um obstáculo para o escoamento superficial no solo, aumentando a infiltração da água e diminuindo consequentemente as vazões máximas. Este comportamento foi observado para os anos de 1992, onde apresentou-se considerável redução da vegetação e a vazão máxima apresentou o maior valor assim como para o ano de 1998 onde a vazão máxima apresentou o menor valor e ocorreu um aumento da classe Mata Ciliar.

Em referência à classe Cerrado e vazão média, deveria ocorrer uma correlação negativa, de acordo com Collischonn et al. (2001). Esperava-se que com o aumento de Cerrado haveria uma redução nos valores da vazão média, devido ao aumento do consumo de água por evapotranspiração. Santos et al. (2010) constatou ao avaliar a relação entre uso do solo e comportamento hidrológico na Bacia Hidrográfica do Ribeirão João Leite, cuja vegetação predominante é o cerrado, que a expansão da área de agricultura indica tendência de aumento das vazões médias.

De modo geral, a falta de correlação entre as classes de uso e ocupação do solo com as vazões e consequentemente com a inercia hídrica da bacia, pode ser explicado pelo fato que, conforme Almeida (2007), a razão entre o volume de água e de energia que circula em bacias de larga escala é muito grande, o que provavelmente ameniza os efeitos hidrológicos das mudanças de uso e de cobertura do solo. Como a bacia do rio Uruçuí-Preto possui uma extensa área, sendo caracterizada como uma bacia de grande porte, esse fato pode justificar a falta de correlação entre as variáveis estudadas.

\section{CONCLUSÕES}

Entre 1984 e 2007 ocorreu a substituição das áreas de cerrado por áreas agrícolas. Não ocorreram correlações significativas entre as variáveis de classes de mudanças no uso e ocupação dos solos e as vazões, porém não se pode afirmar que a mudança no uso e ocupação do solo não afeta a disponibilidade hídrica da bacia do rio Uruçuí-Preto. A extensa área da bacia amenizou consequentemente os efeitos hidrológicos

Para eventuais pesquisas futuras recomenda-se considerar outros fatores que controlam a dinâmica hidrológica de uma bacia hidrográfica, como a precipitação, características fisiográficas e geologia assim como uma maior série temporal de estudo.

\section{REFERÊNCIAS}

ALMEIDA, A. Q. Influência do desmatamento na disponibilidade hídrica da bacia hidrográfica do Córrego do Galo, Domingos Martins, ES. 2007. 92f. Dissertação (Mestrado em Engenharia Ambiental) Universidade Federal do Espírito Santos, Vitória. 2007.

ALMEIDA, I. K.; ALVES SOBRINHO, T.; SANTOS, B. B. dos; STEFFEN, J. L.; BACCHI, C. G. V. Métodos estatísticos na determinação de vazão de referência. Comunicata Scientiae, v. 5, n. 1, p. 11-17, 2014.

AQUINO, R. P.; VALLADARES, G. S.; AQUINO, C. M. S.; GUIMARÃES, C. C. B.; COELHO, R. M. Análise da vulnerabilidade natural e do risco de degradação no alto curso do rio Banabuiu-CE. Revista Brasileira de Geografia Física, v. 9, n. 2, p. 601-613, 2016.

ARAUJO, A. P.; ROCHA, P. C. Regime de fluxo e alterações hidrológicas no rio Tibagi-bacia do rio Paranapanema / Alto Paraná. Revista de Geografia, Recife, v. 7, n. 3. 2010

BRASIL_MINISTÉRIO DA SAÚDE. Vigilância e controle da qualidade da água para consumo humano. Brasília: Ministério da Saúde, 2006. 212 p.

BOSCH, J. M.; HEWLETT, J. D. A review of catchment experiments to determine the effect of vegetation changes on water yield and evapotranspiration. Journal of Hydrology, Amsterdam, v. 55, n. 1-4, p. 3-23, 1982. DOI: https://dx.doi.org/10.1016/0022-1694(82)90117-2

BUTT, A.; SHABBIR, R.; AHMAD, S. S.; AZIZ, N. Land use change mapping and analysis using Remote Sensing and GIS: A case study of Simly watershed, Islamabad, Pakistan. The Egyptian Journal of Remote Sensing and Space Science, v. 18, n. 2, p. 251-259, 2015. DOI: http://dx.doi.org/10.1016/j.ejrs.2015.07.003

COLLISCHONN, W.; TUCCI, C. E. M.; CLARKE, R. T. Further evidence of changes in the hydrological regime of the River Paraguay: Part of a wider phenomenon of climate change? Journal of Hydrology, Amsterdam, v. 245, n. 14, p.218-238, 2001. DOI: https://dx.doi.org/10.1016/S0022-1694(01)00348-1

COSTA, M. H.; BOTTA, A.; CARDILlE, J. A. Effects of large-scale changes in land cover on the discharge of the 
Tocantins River, Southeastern Amazonia. Journal of Hydrology, Amsterdam, v. 283, n. 1-4, p. 206-217, 2003. DOI: https://dx.doi.org/10.1016/S0022-1694(03)00267-1

DELLAMATRICE, P. M.; MONTEIRO, R. T. R. Principais aspectos da poluição de rios brasileiros por pesticidas. Revista Brasileira de Engenharia Agrícola e Ambiental, Campina Grande, v. 18, n. 12, p. 1296-1301, 2014. DOI: http://dx.doi.org/10.1590/18071929/agriambi.v18n12p1296-1301

FRANÇA, L. C. J.; OLIVEIRA, R. J. de; RIBEIRO, N. M. A. R.; SANTOS, E. L.; NORONHA, F. C. C.; RIBEIRO, A. T. Caracterização da cobertura vegetal e uso do solo no município de Uruçuí, Piauí, Brasil. Nativa, Sinop, v. 5, n. 5, p. 337-341, 2017. DOI: http://dx.doi.org/10.5935/23187670.v05n05a06

HEWLETT, J. D. Principles of Forest Hydrology. The University of Georgia Press, 1982. 183 p.

MEDEIROS, R. M.; SILVA, V.P. R.; FILHO, M. F. G. Análise hidroclimática da bacia hidrográfica do rio Uruçuí Preto - Piauí. Revista de Engenharia e Tecnologia, Ponta Grossa, v. 5, n. 4, p. 151-163. 2013.

MOREIRA, M. C.; SILVA, D. D.; SILVA, M. P. Atlas hidrológico da bacia hidrográfica do rio Grande. Revista de Engenharia e Tecnologia, Ponta Grossa, v. 6, n. 2, p. 47-58, 2014.

NERY, C. V. M.; MOREIRA, A. A.; FERNANDES, F. H. C.; ALMEIDA, R. P. Uso do Sensoriamento Remoto na Detecção de Mudança na Microrregião de Montes Claros/MG. Revista Brasileira de Geografia Física, Recife, v. 7, n. 1, p. 130-145, 2014.

PIAUÍ_PORTAL DO GOVERNO DO ESTADO DO PIAUÍ. Produção agrícola piauiense deverá crescer $18 \%$ este ano. 2016. Disponível em: $<$ http://www.piaui.pi.gov.br/noticias/index/categoria/3/id/ 20796>. Acesso em: 15 de ago. 2016.

PULLANIKKATIL, D.; PALAMULENI, L.; RUHIIGA, T. Assessment of land use change in Likangala River catchment, Malawi: A remote sensing and DPSIR approach. Applied Geography, Oxford, v. 71, p. 9-23, 2016.

DOI: http://dx.doi.org/10.1016/j.apgeog.2016.04.005

SANTOS, C. O espírito do capitalismo na ocupação dos cerrados brasileiros nos estados da Bahia e do Piauí. GOT - Geography and Spatial Planning Journal, Porto, n. 8, p. 229-253, 2015. DOI: http://dx.doi.org/10.17127/got/2015.8.012

SANTOS, E. H. M.; GRIEBELER, N. P.; OLIVEIRA, L. F. C. Relação entre uso do solo e comportamento hidrológico na Bacia Hidrográfica do Ribeirão João Leite. Revista Brasileira de Engenharia Agrícola e Ambiental, Campina Grande, v. 14, n. 8, p. 826-834, 2010. DOI: http://dx.doi.org/10.1590/S1415-43662010000800006

SILVA, J. B. L.; SOUSA, P. A. de; SOUZA, K. B.; ALMEIDA, K. N. S. de; PIRES, L. C. Evolução temporal do desmatamento na Bacia do Riacho da Estiva, Piauí. Engenharia na Agricultura, Viçosa, v. 23, n. 4, p. 363370, 2015a. DOI: http://dx.doi.org/10.13083/14143984/reveng.v23n4p363-370

SILVA, J. B. L.; FERREIRA, W. L.; ALMEIDA, K. N. S.; SOUZA, K. B.; NOBREGA, J. C. A. Evolução temporal do desmatamento e expansão agrícola entre 1984 a 2010 na sub-bacia do rio Uruçuí-Preto, Piauí. Engenharia na
Agricultura, Viçosa, v. 22, n. 3, p. 254-261, 2014. DOI: http://dx.doi.org/10.13083/1414-3984.v22n03a08

SILVA, M. B. S.; SILVA, D. D.; MOREIRA, M. C. Influência da sazonalidade das vazões nos critérios de outorga de uso da água: estudo de caso da bacia do rio Paraopeba. Revista Ambiente e Água, Taubaté, v. 10 n. 3, p. 623-634, 2015 b. DOI: http://dx.doi.org/10.4136/ambi-agua.1587

TUCCI, C. E. M. Hidrologia: ciência e aplicação. 4. ed. Porto Alegre: Editora da UFRGS/ABRH, 2009. 943 p.

TUCCI, C. E. M. Impactos da variabilidade climática e uso do solo sobre os recursos hídricos. Brasília: ANA, 2002. $150 \mathrm{p}$.

VANZELA, L.S.; HERNANDEZ, F.B.T.; FRANCO, R.A.M. Influência do uso e ocupação do solo nos recursos hídricos do Córrego Três Barras, Marinópolis. Revista Brasileira de Engenharia Agrícola e Ambiental, Campina Grande, v. $14, \quad$ n. $1, \quad$ p. 55-64, 2010. DOI: http://dx.doi.org/10.1590/S1415-43662010000100008

ZHU, X.; LIU, D. Improving forest aboveground biomass estimation using seasonal Landsat NDVI time-series. ISPRS Journal of Photogrammetry and Remote Sensing, Amsterdam, v. 102, p. 222-231, 2015. DOI: http://dx.doi.org/10.1016/j.isprsjprs.2014.08.014 